\title{
The cytokine alterations/abnormalities and oxidative damage in the pancreas during hypertension development
}

\author{
Anna Kozłowska ${ }^{1} \cdot$ Paweł Wojtacha ${ }^{2} \cdot$ Michał Majewski $^{3} \cdot$ Maciej Równiak $^{4}$
}

Received: 12 June 2019 / Revised: 30 August 2019 / Accepted: 20 September 2019 / Published online: 17 October 2019

(C) The Author(s) 2019

\begin{abstract}
The aim of the present study was to compare the content of cytokines, chemokines, and oxidative stress markers in the pancreas of spontaneously hypertensive rats (SHRs) and Wistar Kyoto Rats (WKYs) serving as controls. Enzyme-like immunosorbent assay (ELISA) and biochemical methods were used to measure pancreatic levels of interleukin-1 $\beta$, interleukin-6, tumor necrosis factor $\alpha$, transforming growth factor $\beta$, RANES, monocyte chemoattractant protein 1, interferon gamma-induced protein 10, malondialdehyde, and sulfhydryl groups. The results showed that the pancreatic concentrations of all studied cytokines and chemokines did not differ between 5-week-old SHRs and WKYs, except RANTES which was significantly reduced in juvenile SHRs. In 10-week-old animals, except interleukin-1ß, the levels of all these proteins were significantly reduced in SHRs. The pancreatic levels of malondialdehyde were significantly reduced in 5-week-old SHRs and significantly elevated in 10-week-old SHRs while the contents of sulfhydryl groups were similar in both rat strains at any age studied. In conclusion, these data provide evidence that in maturating SHRs, the pancreatic levels of cytokines and chemokines are significantly reduced, while malondialdehyde significantly elevated. This suggests that in the pancreas of mature SHRs, the inflammation process is suppressed but there is ongoing oxidative damage.
\end{abstract}

Keywords Pancreas $\cdot$ Hypertension $\cdot$ SHR rats $\cdot$ Cytokines $\cdot$ Chemokines $\cdot$ Oxidative stress markers

\section{Introduction}

It is generally known that the pancreas is an exocrine and endocrine organ. These functions are performed by acinar cells responsible for secretion of the pancreatic juice containing various digestive enzymes and endocrine cells responsible for release of pancreatic hormones such as glucagon ( $\alpha$ cells); insulin, amylin, and C-peptide ( $\beta$ cells); pancreatic polypeptide $(\gamma$ cells); somatostatin $(\delta$ cells $)$; and ghrelin $(\varepsilon$ cells) $[7$,

Anna Kozłowska

kozlowska.anna@uwm.edu.pl

1 Department of Human Physiology, School of Medicine, Collegium Medicum, University of Warmia and Mazury, Olsztyn, Poland

2 Department of Industrial and Food Microbiology, Faculty of Food Science, University of Warmia and Mazury, Olsztyn, Poland

3 Department of Pharmacology and Toxicology, School of Medicine, Collegium Medicum, University of Warmia and Mazury, Olsztyn, Poland

4 Department of Animal Anatomy and Physiology, Faculty of Biology and Biotechnology, University of Warmia and Mazury, Olsztyn, Poland
13, 33, 72]. It should be kept in mind, however, that under physiological conditions there are many external factors affecting exocrine and/or endocrine pancreatic secretion such as some hypothalamic neuropeptides (ghrelin, orexin A and B), cholecystokinin, serotonin and/or melatonin [13].

Pancreatic hormones play especially an important role in the regulation of glucose homeostasis [61]. Thus, dysfunctions of this organ usually lead to diabetes mellitus. On the other hand, diabetes mellitus may change the morphology and functions of the pancreas and can lead to other serious disorders [53]. For example, it was reported that type 1 and type 2 diabetes usually lead to the reduction of the pancreatic volume $[44,47]$. Moreover, irregular pancreatic morphology associated with the decrease in the number of insulin-producing $\beta$ cells was also observed in diabetic patients [9, 17, 37, 49]. In both types of diabetes, a deficit of $\beta$ cell mass leads to insulin deficiency and hyperglycemia $[27,66]$. It is worth mentioning that diabetes might be associated with chronic pancreatitis as well as pancreatic cancer [25-26]. It was also found that the inflammatory processes alone are highly involved in pancreatic cancer pathogenesis [28]. For pancreatic cancer, a recent study showed that hypertension can also increase the risk of this disease [39]. Moreover, many years ago, 
a relationship between acute pancreatitis and malignant hypertension with renal failure was also demonstrated [5].

Hypertension is one of the most common causes of mortality in both, developed and developing countries. As hypertension is a very serious social problem, several experimental animal models were developed as a valuable tool to study the etiology, pathophysiology, and treatment of this disease [39]. One of these models, which spontaneously develops hypertension without any involvement of pharmacological and/or surgical methods, is the genetic strain of hypertensive rat known as the spontaneously hypertensive rat (SHR) [52]. Moreover, SHR is not only a model of hypertension but it also displays various consequences associated with this condition such as cardiac hypertrophy, cardiac failure, and renal dysfunction [38].

Our previous work with the use of SHR model to study selected factors responsible for pathogenesis of ADHD [36] revealed that the levels of various cytokines (interleukin-1 $\beta$ : IL-1 $\beta$, IL-6, tumor necrosis factor alfa and transforming growth factor beta), chemokines (regulated on activation, normal $\mathrm{T}$ cell expressed and secreted, monocyte chemoattractant protein-1, and interferon gamma-induced protein 10), and oxidative stress markers (malondialdehyde and sulfhydryl group) in the serum and/or spleen were significantly elevated in 5-week-old SHR rats (SHRs) when compared to agematched control strain (Wistar Kyoto Rats, WKYs). However, to the best of our knowledge, there is no data available regarding the pancreatic content of these substances in the juvenile (5-week-old) and maturating (10-week-old) SHRs and WKYs. Such data seems to be important because it was earlier reported that an adult SHR develops spontaneous pancreatitis [54]. Moreover, it develops also hypertension [45], and recent evidence clearly demonstrated that sustained hypertension increases pancreatic oxidative stress which might lead to the pancreas damage in the hypertensive rats [23]. Thus, it seems that elevated levels of cytokines, chemokines, and oxidative stress markers observed in the serum and/or spleen of juvenile SHRs might be involved in development of pancreatitis in the maturating animals [36]. To test this hypothesis, enzyme-linked immunosorbent assay was used to detect the pancreatic levels of cytokines and chemokines. Furthermore, biochemical methods were used to investigate the oxidative stress markers in this organ.

\section{Materials and methods}

\section{Animals}

Juvenile (5-week-old) and maturating (10-week-old) male spontaneously hypertensive rats (SHRs, $n=12$ ) and Wistar Kyoto Rats (WKYs, $n=12$ ) were used in the present study. Both these time points of the rat's lifetime were intentionally chosen. Considering that pre-pubertal SHRs are characterized primarily by ADHD abnormalities and symptoms [30], and they are devoid of hypertension [57], 5-week-old animals were selected for investigation. In post-pubertal and mature SHRs, ADHD symptoms disappear [30] but hypertension develops [57]; thus, 10week-old animals were chosen. Both SHRs and WKYs aged 3week were provided by Charles River (Germany). All subjects were housed in groups of two or three in sanitized polypropylene cages (to prevent isolation stress) under controlled temperature $\left(21 \pm 1{ }^{\circ} \mathrm{C}\right), 12 / 12$-h light/dark cycle (lights on $06: 00$ to 18:00) and ventilated (12-20 exchanges/h) animal room. All animals were fed with a grain mixture (VRF1 diet; Charles River, Germany) and tap water ad libitum. All experiments were carried out in accordance with the European Union Directive for animal experiments (2010/63/EU) and approved by the Local Ethical Commission of the University of Warmia and Mazury in Olsztyn (no. 43/2014). All efforts were made to minimize animal suffering and to use the minimum number of animals necessary to produce reliable scientific data.

\section{Experimental procedure}

Following the habituation phase, the experimental rats were divided into four groups according to study design: (1) 5week-old SHR rats ( $n=6$; b.w. 111.1-123.38 g); (2) 5week-old WKY rats ( $n=6$; b.w. 111.25-130.96 g); (3) 10week-old SHR rats ( $n=6$; b.w. 254.72-281.38 g), and (4) 10week-old WKY rats ( $n=6$; b.w. 247.33-266.95 g).

\section{Pancreas collections}

Rats were deeply anesthetized with an intraperitoneal injection of Morbital (Biowet, Poland; $50 \mathrm{mg} / \mathrm{kg}$ ); then, the pancreases were carefully dissected from all studied animals. All these tissue samples were immediately placed in liquid nitrogen $\left(-196^{\circ} \mathrm{C}\right)$ for $30 \mathrm{~min}$ and then stored at low temperature $\left(-80^{\circ} \mathrm{C}\right)$ for further analyses.

\section{Immunoenzymatic determination (ELISA) of cytokines, chemokines, and oxidative stress biomarkers in the pancreas}

To determine concentrations of cytokines, chemokines, and oxidative stress markers in the rat tissues, commercial ELISA Kits were used according to the manufacturer's instructions (Table 1). The absorbance in ELISA test plate was measured by plate reader TECAN infinite $\mathrm{m} 200$ pro (Austria) at the wavelength $\lambda=492 \mathrm{~nm}$.

\section{Measurement of malondialdehyde and sulfhydryl group in the pancreas}

The level of malondialdehyde (MDA) and sulfhydryl groups (-SH) was measured according to the method described earlier 
Table 1 The ELISA kits used for the determination of cytokine and chemokine concentrations in the present study

\begin{tabular}{|c|c|c|c|c|}
\hline & Antigen & ELISA kit catalogue number & Manufacturer, country & Assay range (pg/ml) \\
\hline 1. & RAT IL-1 $\beta$ & $\begin{array}{l}\text { Rat IL-1 } \beta \text { Mini ABTS ELISA Development Kit } \\
900-M 91\end{array}$ & Peprotech, USA & $\begin{array}{l}63-4000 \mathrm{pg} / \mathrm{ml} \\
\text { Intra-assay: } \mathrm{CV}<9 \% \\
\text { Inter-assay: } \mathrm{CV}<10 \%\end{array}$ \\
\hline 2. & RAT IL-6 & $\begin{array}{l}\text { Rat IL-6 Mini ABTS ELISA Development Kit } \\
\text { 900-M86 }\end{array}$ & Peprotech, USA & $\begin{array}{l}31-2000 \mathrm{pg} / \mathrm{ml} \\
\text { Intra-assay: } \mathrm{CV}<9 \% \\
\text { Inter-assay: } \mathrm{CV}<10 \%\end{array}$ \\
\hline 3. & RAT TNF- $\alpha$ & $\begin{array}{l}\text { Rat TNF- } \alpha \text { Mini TMB ELISA Development Kit } \\
900-\text { TM73 }\end{array}$ & Peprotech, USA & $\begin{array}{l}47-6000 \mathrm{pg} / \mathrm{ml} \\
\text { Intra-assay: } \mathrm{CV}<9 \% \\
\text { Inter-assay: } \mathrm{CV}<10 \%\end{array}$ \\
\hline 4. & TGF $\beta$ & TGF beta-1 Multispecies Matched Antibody Pair, CHC1683 & ThermoFisher Scientific, USA & $\begin{array}{l}62.5-4000 \mathrm{pg} / \mathrm{ml} \\
\text { Intra-assay: } \mathrm{CV}<6 \% \\
\text { Inter-assay: CV }<5 \%\end{array}$ \\
\hline 5. & RAT MCP-1 & $\begin{array}{l}\text { Rat MCP-1 (CCL-2) Mini ABTS ELISA Development Kit } \\
\text { 900-M59 }\end{array}$ & Peprotech, USA & $\begin{array}{l}\text { 16-2000 pg/ml } \\
\text { Intra-assay: } \mathrm{CV}<9 \% \\
\text { Inter-assay: } \mathrm{CV}<10 \%\end{array}$ \\
\hline 6. & RAT RANTES & $\begin{array}{l}\text { Rat RANTES (CCL5) Mini ABTS ELISA Development Kit } \\
\text { 900-M72 }\end{array}$ & Peprotech, USA & $\begin{array}{l}16-2000 \mathrm{pg} / \mathrm{ml} \\
\text { Intra-assay: } \mathrm{CV}<9 \% \\
\text { Inter-assay: } \mathrm{CV}<10 \%\end{array}$ \\
\hline 7. & RAT IP-10 & $\begin{array}{l}\text { Rat IP-10 (CXCL10) Mini ABTS ELISA Development Kit } \\
\text { 900-M449 }\end{array}$ & Peprotech, USA & $\begin{array}{l}16-1000 \mathrm{pg} / \mathrm{ml} \\
\text { Intra-assay: } \mathrm{CV}<9 \% \\
\text { Inter-assay: } \mathrm{CV}<10 \%\end{array}$ \\
\hline
\end{tabular}

by Weitner et al. [71] as well as Chan and Wasserman [10], respectively with own modifications. All details concerning both of these methods were described in our previous paper Kozłowska et al. [36].

\section{Statistical analysis}

The Mann-Whitney $U$ test was conducted for significant differences between WKYs and SHRs using GraphPad Prism 6 software (Graph Pad Software, La Jolla, CA, USA). $p<0.05$ was considered to be statistically significant.

\section{Results}

\section{The concentration of cytokines, chemokines, and oxidative stress markers in the pancreas}

In the present study, the levels of almost all cytokines, chemokines, and/or oxidative stress markers (except $-\mathrm{SH}$ groups) differed significantly when animals from both age periods and/or strains were compared.

\section{Cytokines}

The concentrations of interleukin-1ß (IL-1ß), IL-6, tumor necrosis factor $\alpha$ (TNF- $\alpha)$, and transforming growth factor $\beta-1$ (TGF- $\beta$ ) did not differ in 5-week-old SHRs and WKYs (Fig. 1a-d). These concentrations significantly dropped in 10-week-old animals of both rat strains (except TGF- $\beta$ ), but reductions were particularly strong in SHRs. In effect, the concentration of IL-6, TNF- $\alpha$, and TGF- $\beta$ was significantly lower in 10-week-old SHRs when compared to age-matched WKYs (Fig. 1b-d).

\section{Chemokines}

The pattern of chemokine contents was quite similar to that of cytokine contents. For example, these levels were significantly higher in 5-week-old WKYs and SHRs than in their 10-week-old counterparts (Fig. 2a-c). Furthermore, the levels of monocyte chemoattractant protein-1 (MCP-1) and interferon gamma-induced protein 10 (IP-10) did not differ in 5-week-old animals and were significantly reduced in 10-week-old SHRs (Fig. 2a-c). The level of RANTES was significantly reduced in SHRs at any age studied (Fig. 2a).

\section{Oxidative stress markers}

The pancreatic levels of MDA were significantly reduced in 5week-old SHRs when compared to age-matched WKYs (Fig. 3a). In contrast, in 10-week-old SHRs, these levels were significantly elevated (Fig. 3a). The concentrations of-SH did not differ between SHRs and WKYs at any of the age studied and they were quite similar in 5-week-old and 10-week-old animals (Fig. 3b). 

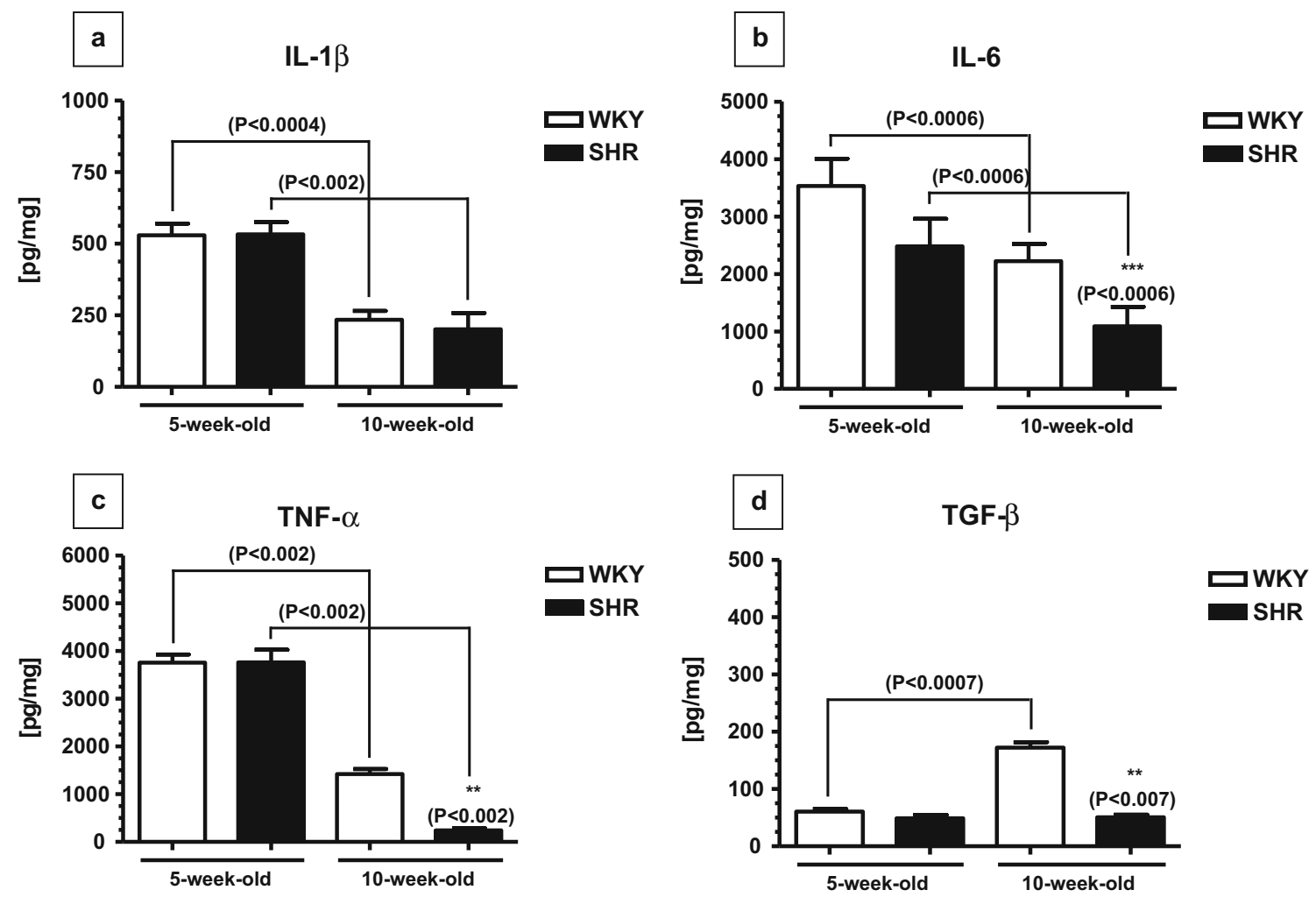

Fig. 1 The level of IL-1ß (a), IL-6 (b), TNF- $\alpha$ (c), and TGF- $\beta$ (d) in the pancreas of SHR $(n=6)$ and WKY rats $(n=6)$. The following statistical levels were applied: $p<0.05$ indicates differences between the juvenile

and mature rats of the same strain; **, *** indicate differences $(p<0.01$; $p<0.001)$ between the SHR and WKY rats

\section{Discussion}

This is the first paper that provides a description of selected cytokines, chemokines, and oxidative stress marker contents in the pancreas of juvenile and maturating SHRs and WKYs. The results show that the pancreatic levels of cytokines and/or chemokines did not differ in juvenile animals of both rat strains but they are significantly reduced in maturating SHRs. The pancreatic levels of MDA were significantly reduced in juvenile SHRs and significantly elevated in maturating SHRs while the content of sulfhydryl groups did not differ in both rat strains at any age studied. These results suggest that in the pancreas of maturating SHRs, the inflammation process is strongly suppressed while in parallel, a slow oxidative damage develops. However, it should be kept in mind that abnormalities observed in the present study are rather before or just at the very beginning of establishing pathological changes as various degenerative alterations in the pancreatic tissues due to spontaneous pancreatitis became evident in SHRs at the age of 12 weeks and they become more prominent or severe in older animals [54].

\section{Pancreatic cytokines}

The present results demonstrate that the pancreatic levels of various cytokines were quite similar in 5-week-old

SHRs when compared to age-matched WKYs. With age in both rat strains, these levels usually undergo significant reductions which were especially strong in SHRs. In effect, the contents of IL-6, TNF- $\alpha$, and TGF- $\beta$ were significantly lower in 10-week-old SHRs when compared to agematched WKYs. These results are very interesting and quite surprising as they significantly differ from the results reporting the pattern of cytokine content in the serum and spleen in our previous study [36]. For example, in the serum and spleen, the levels of IL- $1 \beta$, IL- 6 , and TNF- $\alpha$ were significantly elevated in 5-week-old SHRs when compared to age-matched WKYs whereas in 10-week-old of both rat strains, these levels were similar [36]. It is difficult to explain the reason for these differences because in the available literature, data on this topic is lacking. However, one of the possible explanations is the fact that the inflammation may show unique features in different body organs that was previously observed in the heart tissue of aged rats following severe acute pancreatitis [2]. The results of the present study demonstrate also that the pancreatic levels of IL- $1 \beta$, IL- 6 , and TNF- $\alpha$ were significantly higher in 5-week-old SHRs and WKYs when compared to their 10 -week-old counterparts. Thus, these results coincide well with the studies of Kiely et al. [35] who suggested that the enhanced level of various pro-inflammatory cytokines during $\beta$ cell growth is probably required for their 


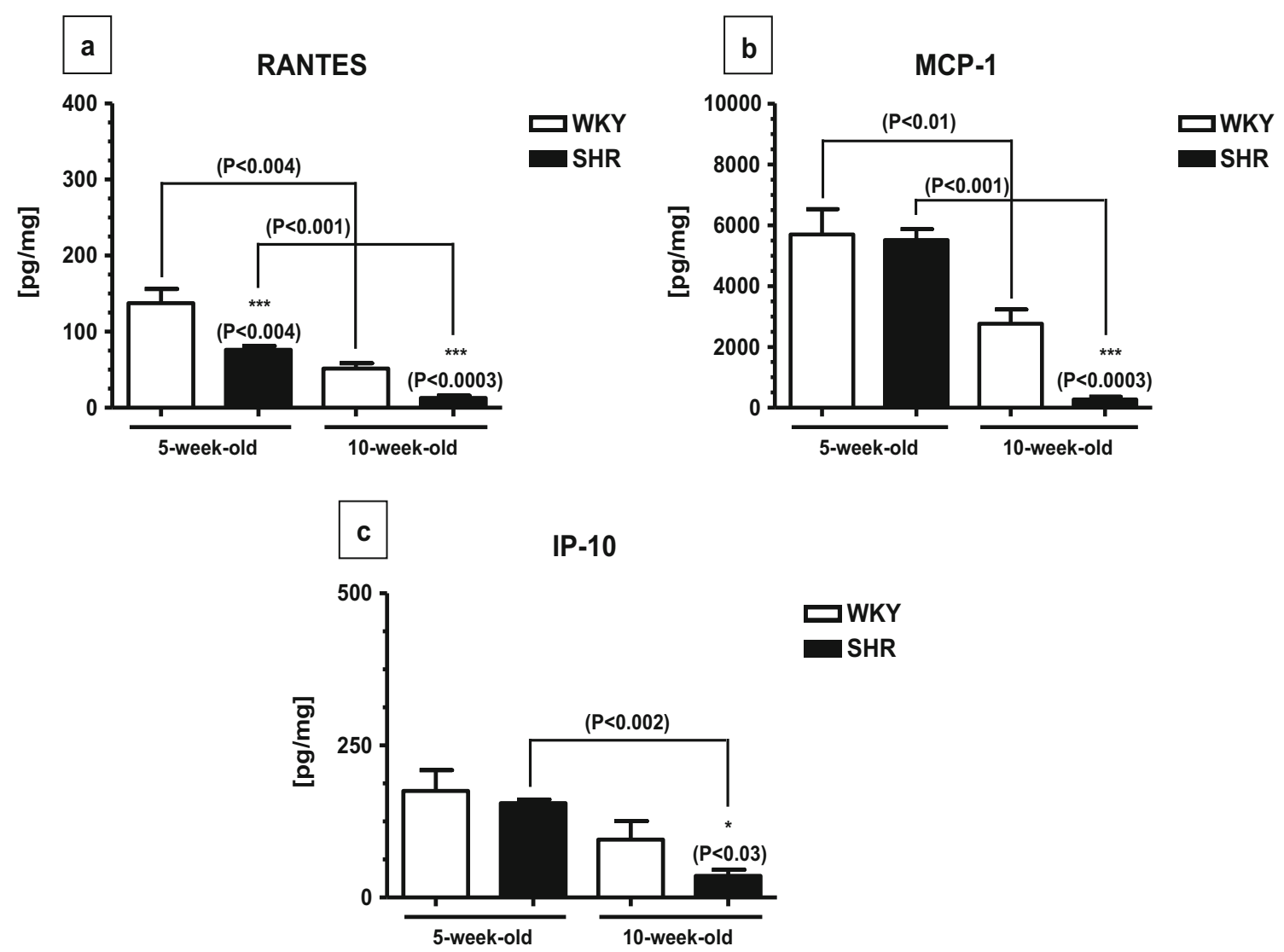

Fig. 2 The level of RANTES (a), MCP-1 (b), and IP-10 (c) in the pancreas of SHR $(n=6)$ and WKY rats $(n=6)$. The following statistical levels were applied: $p<0.05$ indicates differences between

protection and survival. There is also evidence from studies in humans that there is continuous increase of $\beta$ cell mass from neonates through children to reach a stable level in adolescents [65]. The present results show also that the levels of IL-6 and TNF- $\alpha$ were significantly reduced in 10week-old SHRs when compared to age-matched WKYs. Although, data on the pancreatic levels of IL-6 and TNF- $\alpha$ in maturating SHRs is lacking, we can assume that the reduction in these pro-inflammatory cytokine content may be at least partially associated with an elevated serum and/or adrenal contents of progesterone $\left(\mathrm{P}_{4}\right)$ and glucocorticoids (GC) observed in these animals [36-37]. Such supposition may be supported by well-known facts that $\mathrm{P}_{4}$ and GC might inhibit secretion of IL-6 and TNF- $\alpha[16,24,68]$. Moreover, there is a strong dependence between TNF- $\alpha$ and GC causing that this cytokine might reduce $11 \beta$ hydroxysteroid dehydrogenase types 2 activity and in this way increase GC access to their receptors to modulate the inflammatory response [29]. The pattern of TGF- $\beta$ content in the present study was quite different from that of IL-6 and TNF- $\alpha$. For example, the level of this cytokine was significantly higher in maturating WKYs than in juvenile WKYs. The reason for this increase is not fully understood. However, there is evidence that higher level of the juvenile and mature rats of the same strain; *, *** indicate differences $(p<0.05 ; p<0.001)$ between the SHR and WKY rats

TGF- $\beta$ promotes Foxp 3 expressing Treg cells which are critical in maintaining self-tolerance and immune homeostasis $[69,78]$. Thus, it is plausible that in this way 10 week-old WKYs developed immune tolerance [48, 77]. On the other hand, the levels of TGF- $\beta$ in SHRs did not change with age and in effect being significantly lower in 10 -week-old SHRs than in 10-week-old WKYs. Significantly reduced content of TGF- $\beta$ in maturating SHRs was also observed in the spleen [36]. Interestingly, low levels of TGF- $\beta$ together with IL- 6 and IL-21 promote IL-23 receptor expression and in this way stimulate Th17 cell differentiation (by inducing ROR $\gamma \mathrm{t}$ expression) [78]. As Th17 cells play an important role in variety of human autoimmune diseases, it is plausible that lowered TGF- $\beta$ content in maturating SHRs may be a mark of reduced immune tolerance in these animals $[31,78]$.

\section{Pancreatic chemokines}

The present results demonstrate that the pancreatic levels of RANTES, MCP-1, and IP-10 were significantly higher in the 5-week-old SHRs and WKYs than in their maturating counterparts. Furthermore, the levels of MCP-1 and IP-10 did not differ in 5-week-old animals and were significantly 

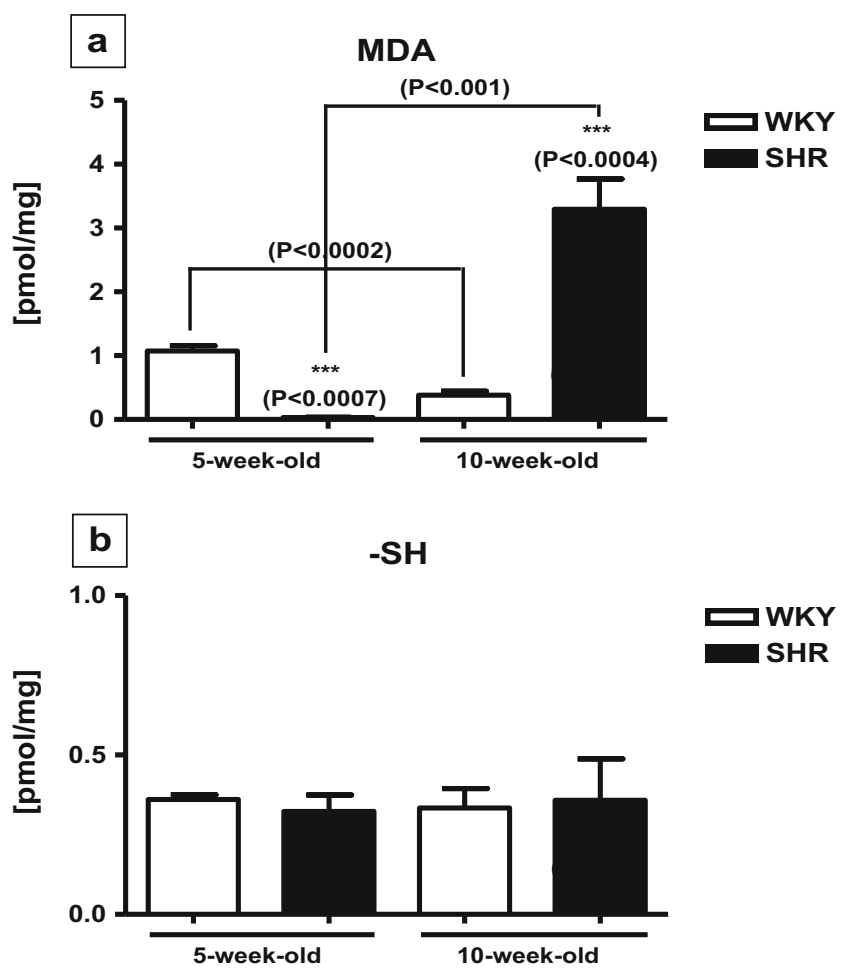

Fig. 3 The level of MDA (a) and -SH (b) in the pancreas of SHR $(n=6)$ and WKY rats $(n=6)$. The following statistical levels were applied: $p<$ 0.05 indicates differences between the juvenile and mature rats of the same strain; $* * *$ indicate differences $(p<0.001)$ between the SHR and WKY rats

reduced in 10-week-old SHRs whereas the level of RANTES was significantly reduced in SHRs at any age studied. Thus, the pattern of pancreatic chemokine contents mimics that of pancreatic cytokine contents and is very different from the pattern of chemokine contents in the serum and spleen [36]. It should be pointed out that there is a lack of data concerning the pancreatic levels of RANTES, MCP-1, and IP-10 in the juvenile and/or maturating SHRs. As of yet, it was only reported that some chemokines might (similarly to cytokines) promote pancreatic $\beta$ cell protection and survival during their development which could explain elevated levels of these proteins in juvenile animals [14]. Moreover, low levels of MCP-1 due to suppression by elevated amounts of $\mathrm{P}_{4}$ and GC were previously observed by several authors $[34,50,76]$ what coincide well with lowered chemokine contents in 10week-old SHRs (present study). Based on the present data, it can be assumed that the low levels of selected chemokines (and pro-inflammatory cytokines) found in the 10-week-old SHRs are not accidental and may play an important role in the attenuation of inflammatory process [42]. However, it should be kept in mind that cytokines and/or chemokines are required during proper pancreas development and in normal pancreatic tissue maintenance. For example, as it was already mentioned, they might promote pancreatic $\beta$ cell protection and survival during development $[14,35]$. These proteins also direct ductalto-endocrine cell differentiation, with implications for $\beta$ cell regeneration (via STAT3-dependent NGN3 activation) [74]. In the mature pancreas, cytokines such as IL-1 $\beta$, IL-6, TNF- $\alpha$, and TGF- $\beta$ seem to be involved in the regulation of pancreatic chemokine, insulin, and/or glucagon secretion $[4,8,41,64]$ while chemokine MCP-1 which is constitutively present in pancreatic islet cells might play a role as a chemotactic factor [56]. The role of cytokines/ chemokines in the pancreatic homeostasis may demonstrate among others studies on $\mathrm{p} 38$ mitogen-activated protein kinase which upregulates various cytokines and chemokines including IL-6, TNF- $\alpha$, and MCP-1 [6] and at the same time suppresses chronic pancreatitis [77].

\section{Pancreatic oxidative stress markers}

The present results revealed that the pancreatic levels of MDA were significantly lower in 5-week-old SHRs when compared to age-matched WKYs whereas in 10-week-old animals, these levels were significantly higher in SHRs than WKYs. The concentrations of -SH did not differ between SHRs and WKYs at any of the age studied. Thus, the pancreatic pattern of oxidative stress markers differs significantly from that in the spleen [36]. For example, in the pancreas, the level of MDA was significantly higher in juvenile than in maturating WKYs while in the spleen, the levels of MDA did not differ between juvenile and maturating rats of the same strain [36]. It is possible that in the pancreas of WKYs, the elevated level of TGF- $\beta$ might modulate lipid peroxidation levels. Such mechanism was reported in rabbits in which during oral mucosal wound healing and after TGF- $\beta$ administration, the nitric oxide and MDA levels increased on the third day to decrease on day 5 after wounding [15]. However, this assumption needs to be verified experimentally, since in the available literature, there is a lack of data addressing this topic in detail. The present results revealed also that the pancreatic level of MDA was significantly reduced in 5week-old SHRs when compared to 5-week-old WKYs and 10 -week-old SHRs. This result is also in contrast with our previous findings in the spleen where the level of MDA was significantly higher in the juvenile SHRs when compared to age-matched WKYs and 10-week-old rats of both strains [36]. We suppose that difference between pancreatic and splenic level of MDA may be a consequence of different oxidative stress levels which is organ specific [32]. In addition, strongly reduced pancreatic level of MDA in 5week-old SHRs might be associated with internal mechanisms that protect the pancreas from oxidative damage. Such protection seems to be especially important in SHRs because in young and adult SHRs, the $\beta$ cell 
component of pancreatic islets is reduced when compared to normotensive Wistar rats [58]. Moreover, the pancreas (especially pancreatic $\beta$ cells) is sensitive to oxidative stress and pancreatic $\beta$ cells had lower levels of antioxidative enzymes when compared to the liver [67, 70]. In turn, strong elevation of pancreatic MDA level in 10-week-old SHRs, observed in the present study, could be associated with progressive oxidative damage of this organ which may lead finally to pancreatitis $[40,51]$. This assumption is supported by the results in adult SHRs in which spontaneous pancreatitis was found [54]. Moreover, it was reported that low expression of the mitochondrial superoxide dismutase (SOD) results in higher concentration of MDA in the SHR brain [11]. Thus, similar situation in the pancreas cannot be ruled out. It is generally accepted that the SOD is the first line of defense against superoxide anion radical $\left(\mathrm{O}^{-} *\right)$ because it catalyzes dismutation of $\mathrm{O}^{-} *$ to hydrogen peroxide [3]. It is plausible that an increase of $\mathrm{O} 2^{-} *$ in SHRs is connected with depletion of the SOD which could lead to peroxidation of lipids and in consequence to the higher level of MDA likewise [12]. However, further studies are necessary. It is worth mentioning here that although elevated levels of MDA in mature SHRs indicate an ongoing oxidative damage of the pancreas, this aldehyde is only the main product of lipid peroxidation [51] and data on other oxidative mechanisms in this organ is still lacking. Protein oxidation, i.e., methionine residue oxidation, tyrosine, or tryptophan residue oxidation could also shed some light in the future on the pancreatic pathology in mature SHRs. The present results indicated also that the pancreatic contents of sulfhydryl groups did not differ in both rat strains at any age studied. This phenomenon may be explained by the fact that $-\mathrm{SH}$ group is closely related with the level of glutathione (GSH) which in cells is the basic antioxidative substance [19]. GSH can react with sulfenic acid and reduce to -SH group [43] which is formed from this group during oxidative stress [46]. Interestingly, TNF- $\alpha$ is one of the most important agents to activate synthesis of GSH [59], and in the present study, the level of TNF- $\alpha$ in maturating SHRs is reduced. On the other hand, low concentration of $-\mathrm{SH}$ group observed in the present study might also be due to the high level of GC [36], which causes depletion of GSH and activity decrease of $\gamma$-glutamylcysteine synthetase what was earlier observed in the alveolar epithelial cells after dexamethasone (synthetic GC) administration [59].

The present results provide evidence that in maturating SHRs, the pancreatic levels of cytokines and chemokines are significantly reduced, while malondialdehyde significantly elevated. This suggests that in the pancreas of mature SHRs, the inflammation process is suppressed but there is ongoing oxidative damage. This may also suggest that in mature SHRs, inflammation is rather inversely correlated with oxidative stress. Generally less inflammation should be correlated to less oxidative stress and such phenomenon is clearly visible in mature WKYs. However, SHRs during lifetime develop ADHD [63] and hypertension [57], and they have significantly altered serum [37] and adrenal [36] concentrations of various steroid hormones which have direct influence on cytokine/chemokine synthesis and oxidative stress. For example, it is widely accepted that $\mathrm{P}_{4}$ and GC might downregulate a great number of cytokines such as IL-1 $\beta$, IL-6, IL-8, IL-12, IL-18, and TNF- $\alpha$ as well as chemokines, such as RANTES and MCP-1 [16, 18, $20-22,24,60,68,73]$. On the other hand, GC might increase oxidative stress [1]. Thus, steroid hormone upregulation in mature SHRs seems to be enough potent factor to downregulate cytokine/chemokine synthesis on the one hand and to increase oxidative stress on the other. Another potent factor which may have huge impact on oxidative stress in mature SHRs is hypertension. For example, recent evidence clearly demonstrated that sustained hypertension increases pancreatic oxidative stress which might lead to the pancreas damage in the hypertensive rats [23]. It is worth mentioning that an anti-inflammatory and protective mechanism in maturing SHRs through steroid hormone upregulation coincides with studies in WBN/Kob rats which are another animal model of chronic pancreatitis. For example, in male WBN/Kob rats, TNF- $\alpha$ and IL6 concentrations peak well before the peak of disease severity what may suggest that both these proteins are involved in the onset of pancreatitis [75]. However, estrogen-treated males and non-treated females (with healthy ovaries producing estrogens and/or $\mathrm{P}_{4}$ ) do not develop pancreas damage suggesting that female sex hormones may be quite efficient protecting mechanism [62]. Steroid hormone levels including $\mathrm{P}_{4}$ and GC are unfortunately unknown in $\mathrm{WBN} / \mathrm{Kob}$ rats and these animals do not develop hypertension. In maturing male SHRs, $\mathrm{P}_{4}$ and GC are highly elevated but estradiol is not [37], and these rats develop hypertension [57]. Thus, it seems that in SHRs, steroid hormone upregulation is sufficient to treat inflammation but it may be insufficient to counteract pancreas damage.

In conclusion, the present study provides evidence that the pancreatic levels of cytokines and/or chemokines are significantly reduced, while MDA significantly elevated in the maturating SHRs when compared to age-matched WKYs. This suggests that in the pancreas of maturating SHRs, the inflammation process is suppressed while in parallel, a slow oxidative damage develops. Moreover, a comparison of the present results with our previous studies [36-37] suggests that both these processes in mature SHRs could be induced by highly elevated levels of steroid hormones which are enough potent to downregulate cytokine/chemokine synthesis and increase oxidative stress. 
Authors' contributions Anna Kozłowska planned the research, analyzed the data, and wrote the paper; Pawel Wojtacha planned the research and performed ELISA and biochemical analyses; Michał Majewski analyzed the data; Maciej Równiak substantively revised the paper.

Funding information This research was funded by the National Centre for Research and Development in Poland, grant number PL-TW II/4/ 2015, and by the School of Medicine, Collegium Medicum, University of Warmia and Mazury in Olsztyn, Poland, statutory grant number 61.610.001-300.

Compliance with ethical standards All experiments were carried out in accordance with the European Union Directive for animal experiments $(2010 / 63 / \mathrm{EU})$ and approved by the Local Ethical Commission of the University of Warmia and Mazury in Olsztyn (no. 43/2014).

Conflict of interest The authors declare that they have no conflict of interest.

Abbreviations ELISA, enzyme-like immunosorbent assay; $G C$, glucocorticoids; $G S H$, glutathione; $I L-1 \beta$, interleukin-1 $\beta$; $I L-6$, interleukin-6; $I L-21$, interleukin-21; IL-23, interleukin-23; IP-10, interferon gammainduced protein $10 ; M C P-1$, chemoattractant protein-1; $M D A$, malondialdehyde; $\mathrm{O}_{2}^{-}$, superoxide anion radical; $P_{4}$, progesterone; RANTES, regulated upon activation, normal T cell expressed and secreted; $-S H$, sulfhydryl groups; $S H R$, spontaneously hypertensive rat; $S O D$, superoxide dismutase; $T G F-\beta$, transforming growth factor $\beta-1 ; T N F-\alpha$, tumor necrosis factor $\alpha$; WKY, Wistar Kyoto Rat

Open Access This article is distributed under the terms of the Creative Commons Attribution 4.0 International License (http:// creativecommons.org/licenses/by/4.0/), which permits unrestricted use, distribution, and reproduction in any medium, provided you give appropriate credit to the original author(s) and the source, provide a link to the Creative Commons license, and indicate if changes were made.

\section{References}

1. Almeida M, Han L, Ambrogini E, Weinstein RS, Manolagas SC (2011) Glucocorticoids and tumor necrosis factor $\alpha$ increase oxidative stress and suppress Wnt protein signaling in osteoblasts. J Biol Chem 286(52):44326-44335. https://doi. org/10.1074/jbc.M111.283481

2. Amaral RC, Barbeiro DF, Koike MK, Mady C, Machado MCC, da Silva FP (2017) Cytokine and chemokine levels in the heart tissue of aged rats following severe acute pancreatitis. Eur J Inflamm 15(2):102-106. https://doi.org/10.1177/1721727X17712398

3. Azadmanesh J, Borgstahl GEO (2018) A review of the catalytic mechanism of human manganese superoxide dismutase. Antioxidants (Basel) 7(2):E25. https://doi.org/10.3390/ antiox7020025

4. Barnes TM, Otero YF, Elliott AD, Locke AD, Malabanan CM, Coldren AG, Brissova M, Piston DW, McGuinness OP (2014) Interleukin-6 amplifies glucagon secretion: coordinated control via the brain and pancreas. Am J Physiol Endocrinol Metab 307(10):E896-E905. https://doi.org/10.1152/ajpendo.00343.2014

5. Barcenas CG, Gonzalez-Molina M, Hull AR (1978) Association between acute pancreatitis and malignant hypertension with renal failure. Arch Intern Med 138(8):1254-1256

6. Blinman TA, Gukovsky I, Mouria M, Zaninovic V, Livingston E, Pandol SJ, Gukovskaya AS (2000) Activation of pancreatic acinar cells on isolation from tissue: cytokine upregulation via p38 MAP kinase. Am J Phys Cell Physiol 279(6):C1993-C2003

7. Brissova M, Fowler MJ, Nicholson WE, Chu A, Hirshberg B, Harlan DM, Powers AC (2005) Assessment of human pancreatic islet architecture and composition by laser scanning confocal microscopy. J Histochem Cytochem 53:1087-1097

8. Burke SJ, Stadler K, Lu D, Gleason E, Han A, Donohoe DR, Rogers RC, Hermann GE, Karlstad MD, Collier JJ (2015) IL-1 $\beta$ reciprocally regulates chemokine and insulin secretion in pancreatic $\beta$-cells via NF-kB. Am J Physiol Endocrinol Metab 309(8):E715E726. https://doi.org/10.1152/ajpendo.00153.2015

9. Butler AE, Janson J, Soeller WC, Butler PC (2003) Increased betacell apoptosis prevents adaptive increase in beta-cell mass in mouse model of type 2 diabetes: evidence for role of islet amyloid formation rather than direct action of amyloid. Diabetes 52(9):2304-2314

10. Chan KY, Wasserman BP (1993) Direct colorimetric assay of free thiol groups and disulfide bonds in suspensions of solubilized and particulate cereal proteins. Cereal Chem 70:22-26

11. Chan P, Liao SS, Hsu CT, Lee YS, Tomlinson B, Kuo JS, Cheng JT (1999) Superoxide dismutase gene expression and activity in the brain of spontaneously hypertensive rats and normotensive rats. Chin Med J 112(12):1119-1124

12. Chan SH, Tai MH, Li CY, Chan JY (2006) Reduction in molecular synthesis or enzyme activity of superoxide dismutases and catalase contributes to oxidative stress and neurogenic hypertension in spontaneously hypertensive rats. Free Radic Biol Med 40(11):2028-2039

13. Chandra R, Liddle RA (2009) Neural and hormonal regulation of pancreatic secretion. Curr Opin Gastroenterol 25:441-446

14. Collier JJ, Sparer TE, Karlstad MD, Burke SJ (2017) Pancreatic islet inflammation: an emerging role for chemokines. J Mol Endocrinol 59(1):R33-R46. https://doi.org/10.1530/JME-17-0042

15. Coșkun Ș, Peker EGG, Balabanlı B, Ahıska S, Acartürk F (2011) Effect of transforming growth factor beta 1 (TGF-beta 1) on nitric oxide production and lipid peroxidation in oral mucosal wound healing. Med Chem Res 20(1):23-28

16. Debets JM, Ruers TJ, van der Linden MP, van der Linden CJ, Buurman WA (1989) Inhibitory effect of corticosteroids on the secretion of tumour necrosis factor (TNF) by monocytes is dependent on the stimulus inducing TNF synthesis. Clin Exp Immunol 78(2):224-229

17. Donath MY, Halban PA (2004) Decreased beta-cell mass in diabetes: significance, mechanisms and therapeutic implications. Diabetologia 47(3):581-589

18. Elenkov IJ, Papanicolaou DA, Wilder RL, Chrousos GP (1996) Modulatory effects of glucocorticoids and catecholamines on human interleukin-12 and interleukin-10 production: clinical implications. Proc Assoc Am Physicians 108:374-381

19. Forman HJ (2016) Glutathione - from antioxidant to posttranslational modifier. Arch Biochem Biophys 595:64-67. https:// doi.org/10.1016/j.abb.2015.11.019

20. Franchimont D, Martens H, Hagelstein MT, Louis E, Dewe W, Chrousos GP, Belaiche J, Geenen V (1999) Tumor necrosis factor alpha decreases, and interleukin-10 increases, the sensitivity of human monocytes to dexamethasone: potential regulation of the glucocorticoid receptor. J Clin Endocrinol Metab 84:2834-2839

21. Fukakusa M, Bergeron C, Tulic MK, Fiset PO, Al Dewachi O, Laviolette M, Hamid Q, Chakir J (2005) Oral corticosteroids decrease eosinophil and $\mathrm{CC}$ chemokine expression but increase neutrophil, IL-8, and IFN-gamma-inducible protein 10 expression in asthmatic airway mucosa. J Allergy Clin Immunol 115(2):280-286. https://doi.org/10.1016/j.jaci.2004.10.036

22. Galon J, Franchimont D, Hiroi N, Frey G, Boettner A, EhrhartBornstein M, O'Shea JJ, Chrousos GP, Bornstein SR (2002) Gene profiling reveals unknown enhancing and suppressive actions of 
glucocorticoids on immune cells. FASEB J 16:61-71. https:/doi. org/10.1096/fj.01-0245com

23. Gao S, Park BM, Cha SA, Bae UJ, Park BH, Park WH, Kim SH (2016) Oxidative stress increases the risk of pancreatic $\beta$ cell damage in chronic renal hypertensive rats. Physiol Rep 4(16):e12900. https://doi.org/10.14814/phy2.12900

24. Giannoni E, Guignard L, Knaup Reymond M, Perreau M, RothKleiner M, Calandra T, Roger T (2011) Estradiol and progesterone strongly inhibit the innate immune response of mononuclear cells in newborns. Infect Immun 79(7):2690-2698. https://doi.org/10.1128/ IAI.00076-11

25. Giovannucci E, Harlan DM, Archer MC, Bergenstal RM, Gapstur SM, Habel LA, Pollak M, Regensteiner JG, Yee D (2010) Diabetes and cancer: a consensus report. Diabetes Care 33(7):1674-1685. https://doi.org/10.2337/dc10-0666

26. Gorelick FS (1983) Diabetes mellitus and the exocrine pancreas. Yale J Biol Med 56(4):271-275

27. Gregory JM, Moore DJ, Simmons JH (2013) Type 1 diabetes mellitus. Pediatr Rev 34(5):203-215. https://doi.org/10.1542/pir. 34-5-203

28. Hausmann S, Kong B, Michalski C, Erkan M, Friess H (2014) The role of inflammation in pancreatic cancer. Adv Exp Med Biol 816: 129-151

29. Heiniger CD, Rochat MK, Frey FJ, Frey BM (2001) TNF-alpha enhances intracellular glucocorticoid availability. FEBS Lett 507(3):351-356

30. Hsieh YL, Yang CC (2008) Age-series characteristics of locomotor activities in spontaneously hypertensive rats: a comparison with the Wistar-Kyoto strain. Physiol Behav 93(4-5):777-782

31. Ivanov II, Zhou L, Littman DR (2007) Transcriptional regulation of Th17 cell differentiation. Semin Immunol 19(6):409-417. https:// doi.org/10.1016/j.smim.2007.10.011

32. Jun J, Savransky V, Nanayakkara A, Bevans S, Li J, Smith PL, Polotsky VY (2008) Intermittent hypoxia has organ-specific effects on oxidative stress. Am J Phys Regul Integr Comp Phys 295(4): R1274-R1281

33. Katsuura G, Asakawa A, Inui A (2002) Roles of pancreatic polypeptide in regulation of food intake. Peptides 23:323-329

34. Kelly RW, Carr GG, Riley SC (1997) The inhibition of synthesis of a b-chemokine, monocyte chemotactic protein-1 (MCP-1) by progesterone. Biochem Biophys Res Commun 239:557-561

35. Kiely A, McClenaghan NH, Flatt PR, Newsholme P (2007) Proinflammatory cytokines increase glucose, alanine and triacylglycerol utilization but inhibit insulin secretion in a clonal pancreatic beta-cell line. J Endocrinol 195(1):113-123. https://doi.org/10. 1677/JOE-07-0306

36. Kozłowska A, Wojtacha P, Równiak M, Kolenkiewicz M (2019) Huang ACW (2019) ADHD pathogenesis in the immune, endocrine and nervous systems of juvenile and maturating SHR and WKY rats. Physiol Res 68:25-36. https://doi.org/10.33549/ physiolres.933907

37. Kozłowska A, Wojtacha P, Równiak M, Kolenkiewicz M, Tsai ML $(2018,2018)$ Differences in serum steroid hormones concentrations in spontaneously hypertensive rats (SHR) - an animal model of attention-deficit/hyperactivity disorder (ADHD). Physiol Res

38. Leong XF, Ng CY, Jaarin K (2015) Animal models in cardiovascular research: hypertension and atherosclerosis Biomed Res Int 528757. https://doi.org/10.1155/2015/528757

39. Lerche O. https://www.express.co.uk/life-style/health/820515/ high-blood-pressure-link-kidney-lung-

40. Leung PS, Chan YC (2009) Role of oxidative stress in pancreatic inflammation. Antioxid Redox Signal 11(1):135-165. https://doi. org/10.1089/ars.2008.2109

41. Lin HM, Lee JH, Yadav H, Kamaraju AK, Liu E, Zhigang D, Vieira A, Kim SJ, Collins H, Matschinsky F, Harlan DM, Roberts AB, Rane SG (2009) Transforming growth factor-beta/Smad3 signaling regulates insulin gene transcription and pancreatic islet beta-cell function. J Biol Chem 284(18):12246-12257. https://doi.org/10. 1074/jbc.M805379200

42. Lira SA, Furtado GC (2012) The biology of chemokines and their receptors. Immunol Res 54(0):111-120. https://doi.org/10.1007/ s12026-012-8313-7

43. Liu RM, Gaston Pravia KA (2010) Oxidative stress and glutathione in TGF- $\beta$-mediated fibrogenesis. Free Radic Biol Med 48(1):1-15. https://doi.org/10.1016/j.freeradbiomed.2009.09.026

44. Löhr M1, Klöppel G (1987) Residual insulin positivity and pancreatic atrophy in relation to duration of chronic type 1 (insulindependent) diabetes mellitus and microangiopathy. Diabetologia 30(10):757-762

45. Louis WJ, Howes LG (1990) Genealogy of the spontaneously hypertensive rat and Wistar-Kyoto rat strains: implications for studies of inherited hypertension. J Cardiovasc Pharmacol 16(7):S1-S5

46. Lu SC (2013) Glutathione synthesis. Biochim Biophys Acta 1830(5):3143-3153. https://doi.org/10.1016/j.bbagen.2012.09.008

47. Macauley M, Percival K, Thelwall PE, Hollingsworth KG, Taylor R (2015) Altered volume, morphology and composition of the pancreas in type 2 diabetes. PLoS One 10(5):e0126825. https://doi.org/ 10.1371/journal.pone. 0126825

48. Mantel PY, Schmidt-Weber CB (2011) Transforming growth factorbeta: recent advances on its role in immune tolerance. Methods Mol Biol 677:303-308. https://doi.org/10.1007/978-1-60761-869-0 21

49. Matveyenko AV, Butler PC (2008) Relationship between $\beta$-cell mass and diabetes onset. Diabetes Obes Metab 10(0 4):23-31. https://doi.org/10.1111/j.1463-1326.2008.00939.x

50. Mukaida N, Zachariae CCO, Gusella GL, Matsushima K (1991) Dexamethasone inhibits the induction of monocyte chemotacticactivating factor production by IL-1 or tumor necrosis factor. J Immunol 146:1212-1215

51. Muñiz P, Coma M, Terán J (2013) Oxidative stress and vascular damage in hypoxia processes. malondialdehyde (MDA) as biomarker for oxidative damage. Electron J Biomed 2(2):50-53

52. Okamoto K, Aoki K (1963) Development of a strain of spontaneously hypertensive rats. Jpn Circ J 27(3):282-293. https://doi.org/ $10.1253 /$ jcj. 27.282

53. Okur ME, Karantas ID, Siafaka P (2017) Diabetes mellitus: a review on pathophysiology, current status of oral medications and future perspectives. Acta Pharm Sci 55(1):61-82. https://doi.org/ 10.23893/1307-2080.APS.0555

54. Onizuka S, Ito M, Sekine I, Tsunoda T, Eto T (1994) Spontaneous pancreatitis in spontaneously hypertensive rats. Pancreas 9(1):54-61

55. Park AM, Kudo M, Hagiwara S, Tabuchi M, Watanabe T, Munakata H, Sakurai T (2012) p38MAPK suppresses chronic pancreatitis by regulating HSP27 and BAD expression. Free Radic Biol Med 52(11-12):2284-2291. https://doi.org/10.1016/j. freeradbiomed.2012.03.010

56. Piemonti L, Leone BE, Nano R, Saccani A, Monti P, Maffi P, Bianchi G, Sica A, Peri G, Melzi R, Aldrighetti L, Secchi A, Di Carlo V, Allavena P, Bertuzzi F (2002) Human pancreatic islets produce and secrete MCP-1/CCL2: relevance in human islet transplantation. Diabetes 51(1):55-65

57. Pinto YM, Paul M, Ganten D (1998) Lessons from rat models of hypertension: from Goldblatt to genetic engineering. Cardiovasc Res 39(1):77-88. https://doi.org/10.1016/S0008-6363(98)00077-7

58. Postnov YV, Gorkova SI, Solovyova LP (1976) Reduction of the beta-cell component of pancreatic islets in spontaneously hypertensive rats. Virchows Arch A Pathol Anat Histol 371(1):79-87

59. Rahman I, Antonicelli F, MacNee W (1999) Molecular mechanism of the regulation of glutathione synthesis by tumor necrosis factoralpha and dexamethasone in human alveolar epithelial cells. J Biol Chem 274(8):5088-5096 
60. Ramírez F, Fowell DJ, Puklavec M, Simmonds S, Mason D (1996) Glucocorticoids promote a TH2 cytokine response by CD4+ T cells in vitro. J Immunol 156:2406-2412

61. Röder PV, Wu B, Liu Y, Han W (2016) Pancreatic regulation of glucose homeostasis. Exp Mol Med 48(3):e219. https://doi.org/10. 1038/emm.2016.6

62. Saegusa T, Kon H, Tsuchitani M, Narama I (1992) Effect of sex hormones on the onset of diabetic syndrome in WBN/Kob rats. Jikken Dobutsu 41(4):481-489

63. Sagvolden T, Johansen EB (2012) Rat models of ADHD. Curr Top Behav Neurosci 9:301-315. https://doi.org/10.1007/7854_2011_126

64. Sato S, Imachi H, Lyu J, Miyai Y, Fukunaga K, Dong T, Ibata T, Kobayashi T, Yoshimoto T, Kikuchi F, Yonezaki K, Yamaji N, Iwama H, Murao K (2018) Effect of TNF- $\alpha$ on the expression of ABCA1 in pancreatic $\beta$-cells. J Mol Endocrinol 61(4):185-193. https://doi.org/10.1530/JME-18-0167

65. Seino S, Bell GI (2008) Pancreatic beta cell in health and disease. In: Rhodes CJ (ed) Regulation of Beta-Cell Growth and Death, 1st edn. Springer Nature, Switzerland AG, pp 215-243

66. Shafiee G, Mohajeri-Tehrani M, Pajouhi M, Larijani B (2012) The importance of hypoglycemia in diabetic patients. J Diabetes Metab Disord 11(1):17. https://doi.org/10.1186/2251-6581-11-17

67. Tiedge M, Lortz S, Drinkgern J, Lenzen S (1997) Relation between antioxidant enzyme gene expression and antioxidative defense status of insulin-producing cells. Diabetes 46(11):1733-1742

68. Waage A, Slupphaug G, Shalaby R (1990) Glucocorticoids inhibit the production of IL6 from monocytes, endothelial cells and fibroblasts. Eur J Immunol 20(11):2439-2443. https://doi.org/10.1002/ eji. 1830201112

69. Wan YY, Flavell RA (2008) TGF-beta and regulatory T cell in immunity and autoimmunity. J Clin Immunol 28(6):647-659. https://doi.org/10.1007/s10875-008-9251-y

70. Wang J, Wang H (2017) Oxidative stress in pancreatic beta cell regeneration. Oxid Med Cell Longev:1930261. https://doi.org/10. $1155 / 2017 / 1930261$
71. Weitner T, Inić S, Jablan J, Gabričević M, Domijan A (2016) Spectrophotometric determination of malondialdehyde in urine suitable for epidemiological studies. Croat Chem Acta 89(1):133139. https://doi.org/10.5562/cca2902

72. Wierup N, Svensson H, Mulder H, Sundler F (2002) The ghrelin cell: a novel developmentally regulated islet cell in the human pancreas. Regul Pept 107:63-69

73. Wingett D, Forcier K, Nielson CP (2011) Glucocorticoid-mediated inhibition of RANTES expression in human T lymphocytes. FEBS Lett 398(2-3):308-311

74. Valdez IA, Dirice E, Gupta MK, Shirakawa J, Teo AKK, Kulkarni RN (2016) Proinflammatory cytokines induce endocrine differentiation in pancreatic ductal cells via STAT3-dependent NGN3 activation. Cell Rep 15(3):460-470. https://doi.org/10.1016/j.celrep.2016.03.036

75. Xie MJ, Motoo Y, Su SB, Sawabu N (2001) Expression of tumor necrosis factor-alpha, interleukin-6, and interferon-gamma in spontaneous chronic pancreatitis in the WBN/Kob rat. Pancreas 22(4):400-408

76. Yang C, Nixon M, Kenyon CJ, Livingstone DEW, Duffin R, Rossi AG, Walker BR, Andrew R (2011) $5 \alpha$-Reduced glucocorticoids exhibit dissociated anti-inflammatory and metabolic effects. Br J Pharmacol 164(6):1661-1671. https://doi.org/10.1111/j.14765381.2011.01465.x

77. Yoshimura A, Wakabayashi Y, Mori T (2010) Cellular and molecular basis for the regulation of inflammation by TGF- $\beta$. J Biochem 147(6):781-792. https://doi.org/10.1093/jb/mvq043

78. Zhou L, Lopes JE, Chong MM, Ivanov II, Min R, Victora GD, Shen Y, Du J, Rubtsov YP, Rudensky AY, Ziegler SF, Littman DR (2008) TGF-beta-induced Foxp3 inhibits T(H)17 cell differentiation by antagonizing RORgammat function. Nature 453(7192):236-240. https://doi.org/10.1038/nature06878

Publisher's note Springer Nature remains neutral with regard to jurisdictional claims in published maps and institutional affiliations. 